\title{
Investigating predictors of examination result data using logistic regression (A case study of Imo State Polytechnic, Umuagwo, Imo State, Nigeria)
}

\author{
Opara Jude ${ }^{1}$, Esemokumo Perewarebo Akpos ${ }^{2,}$, , Iheagwara Andrew Ihuoma ${ }^{3}$, Okenwe Idochi ${ }^{4}$, \\ OSUJI GEORGE A. ${ }^{5}$
}

${ }^{1}$ Department of Statistics, Imo State University, Owerri Nigeria

${ }^{2}$ Federal Polytechnic Ekewe, Yenagoa, Bayelsa State, Nigeria

${ }^{3}$ Department of Statistics, Imo State University, Owerri Nigeria

${ }^{4}$ Department of Statistics, School of Applied Sciences, Rivers State Polytechnic, Bori, Rivers State Nigeria

${ }^{5}$ Department of Statistics, Nnamdi Azikiwe University, PMB 5025, Awka Anambra State Nigeria

\section{Email address:}

judend88@yahoo.com (O. Jude), contactperes@yahoo.com (E. P. Akpos), andyiheagwara@yahoo.com (Iheagwara A. I.), nwonda@yahoo.com (O. Idochi), george.osuji99@yahoo.com (OSUJI G. A.)

\section{To cite this article:}

Opara Jude, Esemokumo Perewarebo Akpos, Iheagwara Andrew Ihuoma, Okenwe Idochi, OSUJI GEORGE A.. Investigating Predictors of Examination Result Data Using Logistic Regression (A Case Study of Imo State Polytechnic, Umuagwo, Imo State, Nigeria). American Journal of Theoretical and Applied Statistics. Vol. 2, No. 6, 2013, pp. 255-267. doi: 10.11648/j.ajtas.20130206.24

\begin{abstract}
This study tends to analyze the school examination results (scores) of 300 randomly selected students of Imo State Polytechnic, Umuagwo near Owerri, Imo State, Nigeria who offer English Language and Mathematics as general courses, using the binary logistic regression model with the aim of examining how some factors (variables) in secondary school level contribute to the performance of the students in the Polytechnic. The analysis is performed on the basis of the explanatory variables viz; gender, type of secondary schools, category of secondary schools, board of examinations and location of secondary schools, where scores of students in English Language and Mathematics are assumed to be the response variables. Applying the method of Correspondence Analysis revealed that there exist a significant correlation between board of examinations and location of schools, which made the analysis to be into two stages. The first stage is based on using English Language and Mathematics as a response variable with gender, type of secondary schools, category of secondary schools, and board of examinations as the explanatory variables. The second stage, on the other hand, English Language and Mathematics is the response variable, while gender, type of secondary schools, category of secondary schools, and location of schools are the explanatory variables. The odds ratio analysis compares the scores obtained in two examinations viz English language and Mathematics. The result of the analysis revealed that females are always showing best performances in Mathematics than English examination in all the two stages carried out in this paper. The study also showed that performances of students from girls' schools are found to be the best in English Language course examination than those of students from boys; secondary schools. Furthermore, the study revealed that government schools always show better performance in English course examination than in Mathematics.
\end{abstract}

Keywords: Odds Ratio, Wald Statistics, Logistic Regression Model, Correspondence Analysis

\section{Introduction}

Neither two students' nor two schools are identical. Students' differ in gender, culture, religion, language, home environment, financial status of parents etc., whereas schools differ in size of students, quality of teacher, infrastructure, location of the school, aid provided by the government etc. Obviously performance of the students measured in terms of scores or grades obtained by them in examination varies from student to student and school to school. The variability in scores is a function of social climate which has to be studied and analyzed scientifically. The history of analyzing the students' performance is as old as history of education. However formal presentation of analysis started around early thirties of the $20^{\text {th }}$ century.

The performance measure corresponding to different 
independent variables may be analyzed using logistic regression analysis. Logistic regression has been successfully employed in social science, biostatistics, genetics and demographic issues, but as far as school examination is concerned, not many research articles are available.

This paper deals with presentation and analysis of examination results of Imo State Polytechnic students Umuagwo, Owerri Nigeria, who offer English language and Mathematics as general courses. The data collected consist of scores of the students in both the examinations in English, and Mathematics courses.

It is assumed that scores of students are affected by social environment controlled by the parameters viz:

(i) Gender (male, female)

(ii) Type of schools (boys', girls' and co-educational)

(iii) Category of schools (Government, non-Government)

(iv) Board of examinations i.e. West African School Certificate Examination (WASCE), National Examination Council (NECO) and National Business for Technical and Examination Board (NABTEB) and

(v) Location of schools (urban, rural).

The logistic regression approach has been adopted to study the examination scores under the variables mentioned above.

Scores of students are partitioned into two sets viz (0 $49)$ and $(50-100)$. Since in the above mentioned examination $50 \%$ and above marks indicate second class, hence the students are classified as belonging to two different categories as far as their scores are concerned. As a consequence idea of binary logistic regression analysis seems to be appropriate when scores are functions of independent variables mentioned above.

\section{Review of Literature}

Iheagwara et al (2013) carried out a research on investigating predictors of incident hypertention using logistic multiple regression. A random sample of 120 patients was selected from Federal Medical Center Owerri, Imo State Nigeria for the study. The data consists of three explanatory variables (Age, gender, BMI) and a response variable (hypertension binary variable). The Logistic regression was explicitly discussed. The SPSS Version 16.0 statistical software package was used for the analysis. From the ROC curve, the area under the curve is 0.903 with $95 \%$ confidence interval $(0.843,0.964)$, which implies that the curve is significantly different from 0.5 since $p$-value is 0.000 meaning that the logistic regression classifies the group significantly better than by chance. The result of the analysis further revealed that only age is significant, while BMI and gender are insignificant, which implies that among all the explanatory variables used in this paper, only age contributes to whether a patient is hypertensive or not. Thus age has an influence on the hypertensive variable of the patients used in this research work.

Soudarssanane et al (2006) carried out a research titled "A key predictors of high blood pressure and hypertension among adolescents: a simple prescription for prevention". A sample of 673 adolescents (351 males, 322 females) in the 15-19 years age group was used for the study. The univariate analysis followed by logistic regression was used as the statistical techniques. The results of the analysis revealed that mean Systolic Blood Pressure (SBP) and mean Diastolic Blood Pressure (DBP) were 113.6 and 74.3 $\mathrm{mm} \mathrm{Hg}$ respectively (114.1 \& 74.6 in males, 113.1 and 74.1 in females). Mean Blood Pressure (MBP) showed significant correlation with age. MBP and prevalence of hypertension increased with social class, salt intake, and parental history of hypertension, weight, height and BMI. Of these, BMI and higher salt intake emerged as independent predictors by multivariate analysis. Findings were confirmed by the case control study, and the major risk factors for hypertension among adolescents are BMI and higher salt intake.

Jewell (2004) admits that linear regression can be used to model risk difference (also called excess risk). However, he immediately followed this with a discussion of the potential for predictions outside of the 0-1 range and then went on to present logistic regression as the model of choice in general.

Kleinbaum and Klein (2002) make the following argument in favour of the logistic function being a reasonable formula for risk:

The S-shape of $f(\mathrm{z})$ has a nice epidemiological property. If we let $f(\mathrm{z})$ represent risk of disease, and let $\mathrm{z}$ represent a combination of risk factors, than an individual's risk is minimal for low z's until some threshold is reached. The risk then rises rapidly over a certain range of intermediate $z$ values, and then remains extremely high (around 1) once $\mathrm{z}$ gets large enough. This threshold idea is thought by epidemiologists to apply to a variety of disease conditions, and so $f(\mathrm{z})$ is widely applicable for considering the multivariable nature of epidemiologic research questions.

Kleinbaum and Klein's argument provides a level of credibility to the logistic function, since logistic regression predicts risk. That is, logistic regression predicts the proportion of 1's in the outcome variable, while forcing the logistic function shape on the predicted values.

Abdalla (2012) researched on application of Multinomial Logistic Regression model which is one of the important methods for categorical data analysis. This model deals with one nominal/ordinal response variable that has more than two categories, whether nominal or ordinal variable. To identify the model by practical way, the researcher used real data on physical violence against children, from a survey of Youth 2003 which was conducted by Palestinian Central Bureau of Statistics (PCBS). Segment of the population of children in the age group (10-14 years) for residents in Gaza governorate, size of 66,935 had been selected, and the response variable consisted of four categories. Eighteen of the explanatory variables were used for building the primary multinomial logistic regression model. Model had been tested through a set of statistical tests to ensure its appropriateness for the data. Also the 
model had been tested by selecting randomly of two observations of the data used to predict the position of each observation in any classified group it can be, by knowing the values of the explanatory variables used. It was concluded by using the multinomial logistic regression model that one will be able to define accurately the relationship between the group of explanatory variables and the response variable, identify the effect of each of the variables, and as well can predict the classification of any individual case.

In this paper, we wish to use binary logistic regression to investigate predictors of examination result data in order to determine how some factors (variables) in secondary schools level contribute to the performance of students in tertiary education.

\section{Methodology}

The logistic regression model assumes that the log-odds of an observation $y$ can be expressed as a linear function of the $r$ input variables $\mathrm{x}$;

$$
\ln \left(\frac{P(x)}{1-P(x)}\right)=\sum_{j=0}^{r} b_{j} x_{j}
$$

In Equation (1), the constant term $\mathrm{b}_{0}$ is added by setting $\mathrm{x}_{0}=1$. This produces $\mathrm{r}+1$ parameters. The left hand side of Equation (1) is called the logit of $\mathrm{P}$, thus which implies logistic regression. have

Taking the exponent of both sides of Equation (1), we

$$
\begin{gathered}
\frac{P(x)}{1-P(x)}=\exp \left(\sum_{j=0}^{r} b_{j} x_{j}\right) \\
=\prod_{j=1}^{r} \exp \left(b_{j} x_{j}\right)
\end{gathered}
$$

Equation (3) tells us that logistic models are multiplicative in their inputs (instead of additive, like a linear model), and it produces a way to interpret the coefficients.

The logit equation can also be inverted to get a new expression for $\mathrm{P}(\mathrm{x})$.

$$
P(x)=\frac{\exp v}{1+\exp v}
$$

where

$$
v=\sum_{j=0}^{r} b_{j} x_{j}
$$

The right hand side of Equation (4) is the sigmoid of $\mathrm{v}$, which maps the real line to the interval $(0,1)$, and is approximately linear near the origin. An important fact about $\mathrm{P}(\mathrm{v})$ is that the derivative $\mathrm{P}^{\prime}(\mathrm{v})=\mathrm{P}(\mathrm{v})[1-\mathrm{P}(\mathrm{v})]$. The derivation goes as follows:

$$
P(v)=\frac{\exp v}{1+\exp v}=(\exp v)(1+\exp v)^{-1}
$$

Solving Equation (6) using the product rule, we have

$$
\begin{aligned}
\mathrm{P}^{\prime}(\mathrm{v}) & =(1+\exp v)^{-1}(\exp v)-(\exp v)(1+\exp v)^{-2}(\exp v) \\
& =\frac{(1+\exp v)(\exp v)}{(1+\exp v)^{2}}-\frac{(\exp v)^{2}}{(1+\exp v)^{2}} \\
& =\frac{\exp v+(\exp v)^{2}-(\exp v)^{2}}{(1+\exp v)^{2}}-\frac{(\exp v)}{(1+\exp v)^{2}}
\end{aligned}
$$

From Equation (9), we have

$$
\begin{aligned}
P^{\prime}(v) & =\frac{\exp v}{1+\exp v} \cdot \frac{1}{1+\exp v} \\
& =\mathrm{P}(\mathrm{v})[1-\mathrm{P}(\mathrm{v})]
\end{aligned}
$$

The solution of a Logistic Regression problem is the set of parameters $\beta$ that maximizes the likelihood of the data, which is expressed as the product of the predicted probabilities of the $\mathrm{N}$ individual observations.

$$
L(X \mid P)=\prod_{i=1, y_{i}=1}^{N} P\left(x_{i}\right) \prod_{i=0, y_{i}=0}^{N}\left[1-P\left(x_{i}\right)\right]
$$

$(\mathrm{X}, \mathrm{y})$ is the set of observations; $\mathrm{X}$ is a $\mathrm{r}+1$ by $\mathrm{N}$ matrix of inputs, where each column corresponds to an observation and the first row is 1 ; $y$ is an $\mathrm{N}$-dimensional vector of responses; and $\left(\mathrm{x}_{\mathrm{i}}, \mathrm{y}_{\mathrm{i}}\right)$ are the individual observations.

Taking the log of Equation (12) we get

$$
L(X \mid P)=\sum_{i=1, y_{i}=1}^{N} \log P\left(x_{i}\right)+\sum_{i=0, y_{i}=0}^{N} \log \left[1-P\left(x_{i}\right)\right]
$$

Maximizing the log-likelihood will maximize the likelihood. The quantity $-2 * \log$-likelihood is called the deviance of the model. It is analogous to the Residual Sum of Squares (RSS) of a linear model. Ordinary least square minimizes RSS; logistic regression minimizes deviance.

$$
\text { Psuedo }-R^{2}=1-\frac{\text { deviance }}{\text { null deviance }}
$$

To maximize the log-likelihood, we take its gradient with respect to $\beta$;

$$
\nabla_{\beta} L=\sum_{\substack{i=0 \\ y_{i}=1}}^{N} \frac{P_{i}^{\prime}}{P_{i}} x_{i}-\sum_{\substack{i=0 \\ y_{i}=1}}^{N} \frac{P_{i}^{\prime}}{1-P_{i}} x_{i}
$$


where $\mathrm{P}_{\mathrm{i}}$ is shorthand for $\mathrm{P}\left(\mathrm{x}_{\mathrm{i}}\right)$. the maximum occurs where the gradient is zero.

Recall that $\mathrm{P}^{\prime}=\mathrm{P}(1-\mathrm{P})$, therefore Equation (15) becomes

$$
\begin{gathered}
\nabla_{\beta} L=\sum_{\substack{i=1 \\
y_{i}=1}}^{N} \frac{P_{i}\left(1-P_{i}\right)}{P_{i}} x_{i}-\sum_{\substack{i=0 \\
y_{i}=0}}^{N} \frac{P_{i}\left(1-P_{i}\right)}{1-P_{i}} x_{i} \\
\nabla_{\beta} L=\sum_{\substack{i=1 \\
y_{i}=1}}^{N}\left(1-P_{i}\right) x_{i}-\sum_{\substack{i=1 \\
y_{i}=0}}^{N} P_{i} x_{i} \\
=\sum_{i=1}^{N}\left[y_{i}\left(1-P_{i}\right)-\left(1-y_{i}\right) P_{i}\right] x_{i}
\end{gathered}
$$

Equation (18) merges the two cases $\left(y_{i}=1\right.$ and $\left.y_{i}=0\right)$ into a single sum. This produces the set of simultaneous equations that are true at the optimum;

$$
\sum_{i=1}^{N} y_{i} x_{i}-P_{i} x_{i}=0
$$

It should be noted that from Equation (19), the sum of probability mass across each coordinate of the $\mathrm{x}_{\mathrm{i}}$ vectors is equal to the count of observations with that coordinate value for which the response was true. For instance, supposing the jth input variable is 1 if the subject is hypertensive, 0 if the subject is not hypertensive. Then

$$
\begin{aligned}
& \sum_{i=1}^{N} y_{i} x_{i j}-P_{i} x_{i j}=0 \\
& \sum_{i=1}^{N} y_{i}-P_{i}=0 \\
& \sum_{\substack{i=1 \\
x_{i j=1}}}^{N} y_{i}=\sum_{\substack{i=1 \\
x_{i j=1}}}^{N} P_{i}
\end{aligned}
$$

The coefficients $\beta$ can be solved using the Newton's method.

Supposing we have a vector function $f: y=f(\beta)$, and we want to obtain the value $\beta_{\text {opt }}$ such that $\mathrm{f}\left(\beta_{\text {opt }}\right)=0$. Assuming that we start with an initial guess $\beta_{0}$, we can take the Taylor expansion of $f$ around $\beta_{0}$ :

$$
F(\beta 0+\Delta) \approx f(\beta 0)+f^{\prime}(\beta 0) \Delta
$$

$\mathrm{f}$ is a matrix, and it is the Jacobean of first derivatives of $\mathrm{f}$ with respect to $\beta$. Setting the left hand side to zero, we then solve for $\Delta$ as follows:

$$
\Delta 0=-\left[f^{\prime}(\beta 0)\right]-1 \mathrm{f}(\beta 0)
$$

We then update our estimate for $\beta$ :

$$
\beta 1=\beta 0+\Delta 0
$$

and iterate until convergence.

In this paper, $\mathrm{f}$ is the gradient of the log-likelihood, and its Jacobean is the Hessian (the matrix of second derivative) of the log-likelihood function.

$$
\begin{aligned}
H & =\frac{\partial \nabla_{\beta} L}{\partial \beta}=-\sum_{i=1}^{N} x_{i} \nabla_{\beta} P_{i} \\
& =\sum_{i=1}^{N} x_{i} P_{i}\left(1-P_{i}\right) x_{i}^{T} \\
& =\mathrm{XWX}^{\mathrm{T}}
\end{aligned}
$$

Where $\mathrm{W}$ is a diagonal matrix of the derivatives $\mathrm{P}^{\prime}{ }_{\mathrm{i}}$ and the ith column of $\mathrm{X}$ corresponds to the ith observation. So we can solve for $\Delta$ at each iteration as

$$
\Delta \mathrm{r}=\left(\mathrm{XWrX}^{\mathrm{T}}\right)^{-1} \mathrm{X}(\mathrm{y}-\mathrm{Pr})
$$

Where $\mathrm{W}$ is the current matrix of derivatives, $\mathrm{y}$ is the vector of observed responses, and $P_{k}$ is the vector of probabilities as calculated by the current estimate of $\beta$.

Comparing this to the solution of a linear regression:

$$
\begin{gathered}
y=X^{T} \beta \\
X y=X X^{T} \beta \\
\beta=\left(X X^{T}\right)^{-1} X y
\end{gathered}
$$

Comparing the two, we can see that at each iteration, $\Delta$ is the solution of a weighted least square problem, where the "response is the difference between the observed response and its current estimated probability of being true.

\section{Data Analysis}

In this paper, binary logistic regression analysis is performed with dependent variables of examination scores of students in English and Mathematics courses of National Diploma (one) in Imo State Polytechnic, Umuagwo, in presence of explanatory variables; gender, type of secondary schools, board of examinations, category of secondary schools and location of secondary schools.

By applying the method of Correspondence Analysis (CA), it is observed that, there exists a significant correlation between board of examinations and location of schools with $r=0.68$. Thus, we perform binary logistic regression analysis.

\subsection{Interpretation of Data}

Table 1. Coding of Variables Affecting Imo Polytechnic Results

\begin{tabular}{llll}
\hline Data Variables & $\begin{array}{l}\text { Data } \\
\text { Explanation }\end{array}$ & Data Type & Conditioned used \\
\hline Dependent Variable & & \\
\hline Examination & & & $0-$ Not satisfied \\
$\begin{array}{l}\text { Scores in Imo } \\
\text { State }\end{array}$ & Not-satisfied & Binary & $1-$ Satisfied \\
Polytechnic & Satisfied & & \\
\hline
\end{tabular}




\begin{tabular}{|c|c|c|c|}
\hline Data Variables & $\begin{array}{l}\text { Data } \\
\text { Explanation }\end{array}$ & Data Type & Conditioned used \\
\hline \multicolumn{4}{|c|}{ Independent Variables } \\
\hline Gender & $\begin{array}{l}\text { Gender of } \\
\text { student }\end{array}$ & Binary & $\begin{array}{l}0-\text { Female } \\
1-\text { Male }\end{array}$ \\
\hline School Type & $\begin{array}{l}\text { Type of } \\
\text { Schools }\end{array}$ & Categorical & $\begin{array}{l}0 \text { - Girls' } \\
1 \text { - Boys' } \\
\text { 2-Co-educational }\end{array}$ \\
\hline Board & $\begin{array}{l}\text { Board of } \\
\text { Examinations }\end{array}$ & Categorical & $\begin{array}{l}0-\text { WASCE } \\
1-\text { NECO } \\
2-\text { NABTEB }\end{array}$ \\
\hline School Category & $\begin{array}{l}\text { Category of } \\
\text { Schools }\end{array}$ & Binary & $\begin{array}{l}0 \text { - Government } \\
1-\text { Non-Government }\end{array}$ \\
\hline Location & $\begin{array}{l}\text { Location of } \\
\text { Schools }\end{array}$ & Binary & $\begin{array}{l}0-\text { - Urban } \\
1-\text { Rural }\end{array}$ \\
\hline
\end{tabular}

Table 2. Categorical Variables Affecting Imo Polytechnic Students'Results

\begin{tabular}{llcc}
\hline Variables & Category & Frequencies & \% \\
\hline \multirow{2}{*}{ Gender } & Female & 186 & 62.00 \\
& (Male) & 114 & 38.00 \\
\multirow{3}{*}{ School Type } & Girls' & 55 & 18.36 \\
& Boys' & 79 & 26.33 \\
& (Co-Education) & 166 & 55.34 \\
Board & WASCE & 148 & 49.33 \\
& NECO & 92 & 30.67 \\
\multirow{5}{*}{ School Category } & (NABTEB) & 60 & 20.00 \\
& Government & 157 & 52.33 \\
Location & (Non-Government) & 143 & 47.67 \\
& Urban & 138 & 46.00 \\
& (Rural) & 162 & 54.00 \\
\hline
\end{tabular}

Here the reference category is shown in parenthesis $\left(2^{\text {nd }}\right.$ column in Table 2)
Table 3 (a). Classification of Total Marks in English Language Course Examination

\begin{tabular}{lcc}
\hline Classification & Frequency & Percentage (\%) \\
\hline Not-Satisfied & 90 & 30 \\
Satisfied & 210 & 70 \\
Total & 300 & 100 \\
\hline
\end{tabular}

Table 3 (b). Classification of Total Marks in Mathematics Course Examination

\begin{tabular}{lcc}
\hline Classification & Frequency & Percentage (\%) \\
\hline Not-Satisfied & 84 & 28 \\
Satisfied & 216 & 72 \\
Total & 300 & 100 \\
\hline
\end{tabular}

By dropping one of the variables which is correlated, i.e., board of examinations and location of schools are not used simultaneously as explanatory variables, we carry out binary logistic regression analysis in two stages. It should be recalled that the second column of the following tables "B" represents the coefficient for the constant (also known as the "intercept") in the model.

\subsection{Stage I Analysis}

In this stage, we consider the examination scores in English course as a dependent variable; where as gender of students, school type, board of examinations, and school category are explanatory variables.

Table 4. Logistic Regression Analysis of Examination Results in English Course of Students in Imo State Polytechnic, Umuagwo

\begin{tabular}{|c|c|c|c|c|c|c|c|c|c|}
\hline \multicolumn{10}{|c|}{ Variables in the Equation } \\
\hline & & \multirow{2}{*}{ B } & \multirow{2}{*}{ S.E. } & \multirow{2}{*}{ Wald } & \multirow{2}{*}{ df } & \multirow{2}{*}{ Sig. } & \multirow{2}{*}{$\operatorname{Exp}(B)$} & \multicolumn{2}{|c|}{ 95.0\% C.I.for EXP(B) } \\
\hline & & & & & & & & Lower & Upper \\
\hline \multirow{8}{*}{ Step $1^{\mathrm{a}}$} & Gender & .138 & .253 & .298 & 1 & .585 & 1.148 & .700 & 1.883 \\
\hline & School Type & & & 7.250 & 2 & .027 & & & \\
\hline & School Type (1) & .771 & .356 & 4.680 & 1 & .031 & 2.162 & 1.075 & 4.349 \\
\hline & School Type (2) & .566 & .290 & 3.800 & 1 & .051 & 1.762 & .997 & 3.113 \\
\hline & Board & & & 3.257 & 2 & .196 & & & \\
\hline & Board (1) & .336 & .241 & 1.942 & 1 & .163 & 1.399 & .872 & 2.245 \\
\hline & Board (2) & .440 & .281 & 2.450 & 1 & .118 & 1.553 & .895 & 2.696 \\
\hline & School Category & .326 & .231 & 2.001 & 1 & .157 & 1.386 & .882 & 2.177 \\
\hline
\end{tabular}

a. Variable(s) entered on step 1: Gender, School Type, Board, School Category.

The Wald Statistic and the corresponding significance level test, the significance of each of the covariate and dummy explanatory variables in the model are shown in Table 4. It should be noted that if the Wald Statistic is significant (i.e. less than 0.05), then the parameter is significant in the model. Among the explanatory variables, gender of students, board of examinations, and school category are insignificant, whereas type of schools have significantly affected the results of students in English course of Imo State Polytechnic, Umuagwo.

As shown in Table 4, type of schools (i.e. girls' and boys' schools) as a whole is a significant factor with p-value 0.027 corresponding to students' results. Also it is noticed that, performance of girls' and boys' schools are 2.162 and 1.762 times better than the co-educational schools respectively. 
The performance of female students is 1.148 times higher than that of the performance of male students, though it is insignificant to the model.

As far as the board of examination is concerned, it is observed that WASCE and NECO boards are 1.399 and 1.553 times better than that NABTEB board. Similarly, it is observed that performances of government schools are 1.386 times better than, the non-Government schools.
Examining the length of confidence interval of estimated odds, we observe that gender (female) of students is estimated with $95 \%$ confidence having shortest interval length.

Here, we consider the examination scores in Mathematics course as a dependent variable; whereas gender of students, school type, board of examinations, and school category are explanatory variables.

Table 5. Logistic Regression of Mathematics Examination Results

\begin{tabular}{|c|c|c|c|c|c|c|c|c|c|}
\hline \multicolumn{10}{|c|}{ Variables in the Equation } \\
\hline & & \multirow{2}{*}{ B } & \multirow{2}{*}{ S.E. } & \multirow{2}{*}{ Wald } & \multirow{2}{*}{ df } & \multirow{2}{*}{ Sig. } & \multirow{2}{*}{$\operatorname{Exp}(B)$} & \multicolumn{2}{|c|}{ 95.0\% C.I.for EXP(B) } \\
\hline & & & & & & & & Lower & Upper \\
\hline \multirow{8}{*}{ Step $1^{\mathrm{a}}$} & Gender & .515 & .251 & 4.216 & 1 & .040 & 1.673 & 1.024 & 2.735 \\
\hline & School Type & & & .378 & 2 & .828 & & & \\
\hline & School Type (1) & -.186 & .317 & .346 & 1 & .557 & .830 & .446 & 1.544 \\
\hline & School Type (2) & -.084 & .278 & .092 & 1 & .761 & .919 & .533 & 1.584 \\
\hline & Board & & & 7.827 & 2 & .020 & & & \\
\hline & Board(1) & .470 & .236 & 3.953 & 1 & .047 & 1.600 & 1.007 & 2.543 \\
\hline & Board(2) & .711 & .278 & 6.526 & 1 & .011 & 2.036 & 1.180 & 3.513 \\
\hline & School Category & .084 & .223 & .143 & 1 & .705 & 1.088 & .702 & 1.686 \\
\hline
\end{tabular}

a. Variable(s) entered on step 1: Gender, School Type, Board, School Category.

Here we consider Mathematics result as the dependent variable, where as gender of students, school type, board of examination, and school category are explanatory variables.

Looking at Table 5, it is observed that gender of students, and board of examination contribute significantly to the model; where type of schools and category of schools are found not to be significant in explaining the satisfactory results in Mathematics.

It is obvious that the performances of female students are 1.673 times higher than that of the performance of male students. On the other hand for type of students, it can be seen that, it is not a significant factor with p-value 0.828 corresponding to examination scores. Hence, it is observed that, performance of girls' and boys' schools are 0.830 and 0.919 times better than the co-educational schools respectively.

As far as board of examinations is concerned, it is observed that, WASCE and NECO boards are 1.600 and 2.036 times better than that of NABTEB board. On the other hand, it is observed that the performances of Government schools are 1.088 times better than the nonGovernment schools.

Looking at the length of confidence interval of estimated odds, we find that category of school is estimated with $95 \%$ confidence having shortest interval length.

Observing the Figure 1, we may conclude that, female performance is better in mathematics examination than that of English Language examination. It is interesting to know that boys' schools also show better performance in English
Language examination. Similarly, performance of WASCE shows better results in English Examination than in Mathematics examination; where as, NECO shows better performance in Mathematics examination than in English examination. Government schools show better performance in English than in mathematics examination.

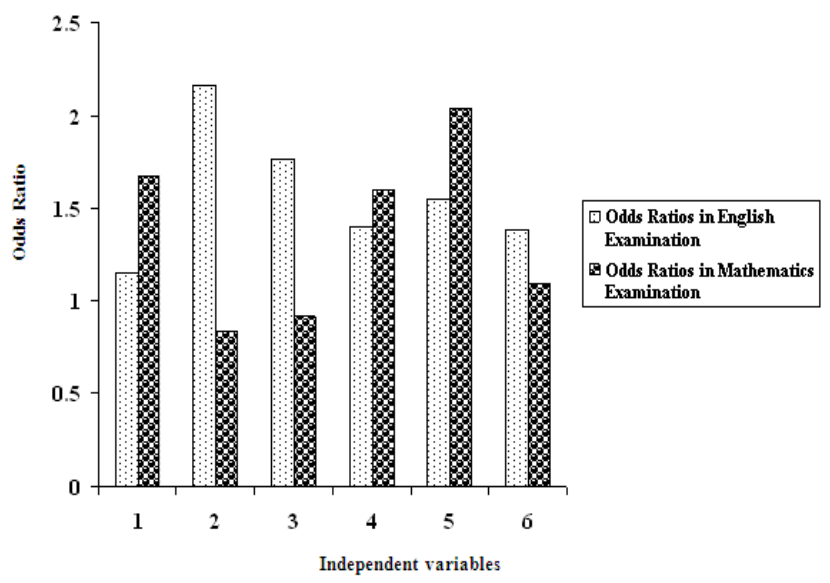

Figure 1. Comparison of Odds Ratios obtained in English Language and Mathematics Examination

\subsection{Stage II Analysis}

In this stage, we consider the examination scores in English course as a dependent variable, where as gender of students, school type, school category and location of schools are explanatory variables. 
Table 6. Logistic Regression Analysis of Examination Results in English Course of Students in Imo State Polytechnic, Umuagwo

\begin{tabular}{|c|c|c|c|c|c|c|c|c|c|}
\hline \multicolumn{10}{|c|}{ Variables in the Equation } \\
\hline & & \multirow{2}{*}{ B } & \multirow{2}{*}{ S.E. } & \multirow{2}{*}{ Wald } & \multirow{2}{*}{ df } & \multirow{2}{*}{ Sig. } & \multirow{2}{*}{$\operatorname{Exp}(B)$} & \multicolumn{2}{|c|}{ 95.0\% C.I.for EXP(B) } \\
\hline & & & & & & & & Lower & Upper \\
\hline \multirow{6}{*}{ Step $1^{\mathrm{a}}$} & Gender & .304 & .238 & 1.641 & 1 & .200 & 1.356 & .851 & 2.159 \\
\hline & School Type & & & 12.798 & 2 & .002 & & & \\
\hline & School Type (1) & .949 & .348 & 7.449 & 1 & .006 & 2.582 & 1.307 & 5.103 \\
\hline & School Type (2) & .758 & .286 & 7.027 & 1 & .008 & 2.133 & 1.218 & 3.736 \\
\hline & School Category & .517 & .218 & 5.602 & 1 & .018 & 1.677 & 1.093 & 2.572 \\
\hline & Location & -.025 & .211 & .014 & 1 & .906 & .975 & .645 & 1.476 \\
\hline
\end{tabular}

a. Variable(s) entered on step 1: Gender, School Type, School Category, Location.

Looking at Table 6, it is observed that school type and school category contribute significantly to the model; where as gender of student and location of schools are found to be insignificant in explaining the satisfactory results in the institution.

Particularly, the performances of female students are 1.356 times higher than that of the performance of male students. On the other hand, for school type (i.e., girls' and boys' schools) as a whole is significant factor with p-value 0.002 corresponding to examination results. Hence, it is observed that, performance of girls' and boys' schools are
2.582 and 2.133 times better than the co-educational schools respectively.

On the other hand, the performances Government schools comparing to the other i.e. non-Government schools are better (with odds ratios 1.677). Similarly, the performances of urban students are 0.975 times better than the rural students.

Looking at the length of confidence interval of estimated odds, we observe that, location of school is estimated with $95 \%$ confidence having shortest interval length.

Table 7. Logistic Regression Analysis of Mathematics Results

\begin{tabular}{|c|c|c|c|c|c|c|c|c|c|}
\hline \multicolumn{10}{|c|}{ Variables in the Equation } \\
\hline & & \multirow{2}{*}{ B } & \multirow{2}{*}{ S.E. } & \multirow{2}{*}{ Wald } & \multirow{2}{*}{ df } & \multirow{2}{*}{ Sig. } & \multirow{2}{*}{$\operatorname{Exp}(B)$} & \multicolumn{2}{|c|}{ 95.0\% C.I.for EXP(B) } \\
\hline & & & & & & & & Lower & Upper \\
\hline \multirow{6}{*}{ Step $1^{\mathrm{a}}$} & Gender & .714 & .236 & 9.121 & 1 & .003 & 2.041 & 1.285 & 3.244 \\
\hline & School Type & & & .400 & 2 & .819 & & & \\
\hline & School Type(1) & .055 & .304 & .033 & 1 & .855 & 1.057 & .582 & 1.919 \\
\hline & School Type(2) & .169 & .270 & .393 & 1 & .531 & 1.184 & .698 & 2.009 \\
\hline & School Category & .312 & .209 & 2.223 & 1 & .136 & 1.366 & .906 & 2.060 \\
\hline & Location & .088 & .205 & .184 & 1 & .668 & 1.092 & .731 & 1.632 \\
\hline
\end{tabular}

a. Variable(s) entered on step 1: Gender, School Type, School Category, Location.

Here, we consider the examination scores in Mathematics course as a dependent variable; where as gender of students, school type, school category and location of schools are explanatory variables.

Looking at Table 7, gender is the only variable found to be significantly contributing to the model.

The performances of female students are 2.041 times higher than that of the performances of male students; whereas performances of Government schools are 1.366 times better than, the non-Government school. Similarly, the performances of urban students are 1.092 times better than the rural students.

As indicated in Table 7, type of schools (i.e. girls' and boys' schools) as a whole is insignificant factor with $\mathrm{p}$ value 0.819 corresponding to examination scores. Hence, it is observed that, performance of girls and boys' schools are 1.057 and 1.184 times better than the co-educational schools respectively.

Looking at the length of confidence interval of estimated odds, we observe that location of school is estimated with 95\% confidence having shortest interval length.

Looking at Figure 2, we may conclude that, female performance is better in mathematics examination than that of English Language examination. It is also interesting to know that boys' schools also show better performance in English Language examination. Government schools show 
better performance in English than mathematics examination. Similarly, urban schools show slightly better performance in mathematics examination.

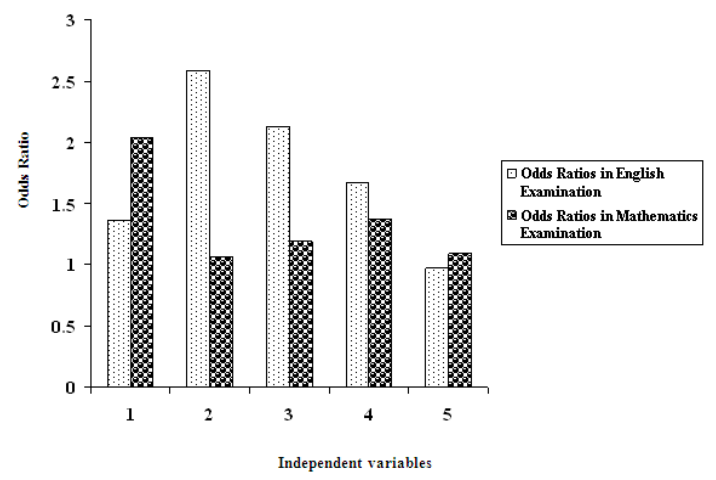

Figure 2. Comparison of Odds Ratios obtained in English Language and Mathematics Examination

\section{Appendix}

\begin{tabular}{|c|c|c|c|c|c|c|c|}
\hline $\mathbf{S} / \mathbf{N}$ & English & Maths & Gender & School type & Board & School Category & Location \\
\hline 1 & 1 & 0 & 0 & 0 & 2 & 0 & 1 \\
\hline 2 & 1 & 1 & 1 & 2 & 0 & 1 & 0 \\
\hline 3 & 1 & 0 & 0 & 1 & 0 & 1 & 0 \\
\hline 4 & 0 & 0 & 1 & 0 & 2 & 0 & 1 \\
\hline 5 & 1 & 1 & 1 & 1 & 1 & 1 & 0 \\
\hline 6 & 0 & 1 & 0 & 2 & 0 & 0 & 1 \\
\hline 7 & 1 & 1 & 1 & 2 & 0 & 1 & 1 \\
\hline 8 & 0 & 1 & 0 & 1 & 1 & 0 & 1 \\
\hline 9 & 1 & 0 & 0 & 0 & 1 & 1 & 1 \\
\hline 10 & 1 & 1 & 0 & 1 & 0 & 0 & 0 \\
\hline 11 & 0 & 0 & 0 & 2 & 0 & 0 & 1 \\
\hline 12 & 1 & 1 & 1 & 2 & 0 & 0 & 0 \\
\hline 13 & 1 & 1 & 0 & 2 & 0 & 0 & 1 \\
\hline 14 & 1 & 1 & 0 & 2 & 1 & 1 & 1 \\
\hline 15 & 1 & 1 & 0 & 0 & 0 & 1 & 0 \\
\hline 16 & 1 & 0 & 0 & 1 & 1 & 0 & 1 \\
\hline 17 & 0 & 0 & 0 & 2 & 0 & 1 & 1 \\
\hline 18 & 1 & 1 & 1 & 1 & 0 & 1 & 0 \\
\hline 19 & 1 & 1 & 1 & 2 & 0 & 0 & 0 \\
\hline 20 & 0 & 0 & 0 & 1 & 1 & 0 & 1 \\
\hline 21 & 1 & 0 & 0 & 2 & 1 & 0 & 1 \\
\hline 22 & 1 & 1 & 0 & 0 & 1 & 1 & 0 \\
\hline 23 & 1 & 1 & 0 & 1 & 0 & 0 & 1 \\
\hline 24 & 0 & 0 & 1 & 2 & 2 & 0 & 0 \\
\hline 25 & 1 & 1 & 1 & 2 & 0 & 1 & 0 \\
\hline 26 & 1 & 1 & 0 & 0 & 0 & 0 & 0 \\
\hline 27 & 1 & 0 & 1 & 1 & 0 & 0 & 0 \\
\hline 28 & 0 & 0 & 0 & 2 & 0 & 0 & 1 \\
\hline 29 & 1 & 1 & 0 & 0 & 1 & 0 & 1 \\
\hline 30 & 0 & 0 & 0 & 2 & 0 & 1 & 0 \\
\hline 31 & 1 & 1 & 0 & 1 & 0 & 0 & 0 \\
\hline 32 & 0 & 0 & 0 & 2 & 0 & 1 & 0 \\
\hline 33 & 1 & 1 & 0 & 0 & 2 & 1 & 0 \\
\hline 34 & 0 & 0 & 1 & 2 & 2 & 0 & 1 \\
\hline 35 & 1 & 1 & 1 & 0 & 0 & 0 & 0 \\
\hline 36 & 1 & 1 & 1 & 2 & 0 & 0 & 1 \\
\hline 37 & 1 & 1 & 0 & 1 & 2 & 1 & 1 \\
\hline 38 & 0 & 0 & 1 & 0 & 1 & 1 & 1 \\
\hline 39 & 1 & 1 & 0 & 1 & 0 & 0 & 1 \\
\hline 40 & 1 & 1 & 0 & 2 & 1 & 0 & 1 \\
\hline 41 & 1 & 1 & 1 & 1 & 0 & 1 & 0 \\
\hline
\end{tabular}

\section{Conclusion}

This study attempts to examine how some factors (variables) contribute to the performances of undergraduate students in English and Mathematics courses examination, in Imo State Polytechnic, Umuagwo. From the analysis carried out in this paper for the two stages, we may conclude that, females are always showing best performances in Mathematics examination than English examination in all the two stages. The performances of girls' schools are found to be best in English course examination. Similarly, Government schools always show better performance in English course examination. 


\begin{tabular}{|c|c|c|c|c|c|c|c|}
\hline $\mathrm{S} / \mathrm{N}$ & English & Maths & Gender & School type & Board & School Category & Location \\
\hline 42 & 0 & 1 & 1 & 2 & 2 & 1 & 0 \\
\hline 43 & 1 & 1 & 1 & 2 & 0 & 0 & 0 \\
\hline 44 & 1 & 1 & 0 & 2 & 1 & 1 & 1 \\
\hline 45 & 1 & 0 & 0 & 2 & 1 & 1 & 1 \\
\hline 46 & 0 & 0 & 0 & 1 & 0 & 0 & 1 \\
\hline 47 & 0 & 1 & 0 & 1 & 0 & 0 & 0 \\
\hline 48 & 1 & 1 & 0 & 2 & 2 & 1 & 0 \\
\hline 49 & 1 & 1 & 0 & 0 & 1 & 0 & 1 \\
\hline 50 & 1 & 0 & 0 & 2 & 0 & 1 & 0 \\
\hline 51 & 0 & 0 & 1 & 0 & 2 & 0 & 0 \\
\hline 52 & 1 & 1 & 1 & 0 & 0 & 0 & 1 \\
\hline 53 & 1 & 1 & 1 & 1 & 2 & 1 & 1 \\
\hline 54 & 1 & 1 & 0 & 2 & 0 & 1 & 1 \\
\hline 55 & 0 & 0 & 1 & 0 & 1 & 0 & 1 \\
\hline 56 & 1 & 1 & 1 & 2 & 0 & 1 & 1 \\
\hline 57 & 1 & 0 & 0 & 1 & 1 & 1 & 1 \\
\hline 58 & 1 & 1 & 0 & 2 & 0 & 0 & 0 \\
\hline 59 & 0 & 1 & 0 & 1 & 0 & 1 & 0 \\
\hline 60 & 1 & 1 & 0 & 2 & 0 & 0 & 0 \\
\hline 61 & 0 & 0 & 0 & 2 & 2 & 1 & 1 \\
\hline 62 & 1 & 1 & 0 & 1 & 2 & 0 & 1 \\
\hline 63 & 1 & 1 & 0 & 2 & 1 & 1 & 1 \\
\hline 64 & 1 & 1 & 0 & 0 & 1 & 0 & 1 \\
\hline 65 & 0 & 1 & 0 & 1 & 0 & 0 & 0 \\
\hline 66 & 1 & 0 & 0 & 2 & 0 & 1 & 0 \\
\hline 67 & 1 & 1 & 1 & 1 & 1 & 0 & 1 \\
\hline 68 & 0 & 0 & 1 & 2 & 0 & 1 & 1 \\
\hline 69 & 1 & 1 & 1 & 2 & 0 & 1 & 0 \\
\hline 70 & 1 & 1 & 1 & 1 & 2 & 0 & 1 \\
\hline 71 & 0 & 0 & 1 & 1 & 0 & 1 & 0 \\
\hline 72 & 1 & 1 & 1 & 1 & 2 & 0 & 0 \\
\hline 73 & 1 & 1 & 1 & 0 & 0 & 1 & 0 \\
\hline 74 & 0 & 0 & 0 & 0 & 0 & 0 & 1 \\
\hline 75 & 0 & 0 & 0 & 0 & 1 & 1 & 1 \\
\hline 76 & 1 & 0 & 0 & 2 & 2 & 1 & 1 \\
\hline 77 & 0 & 0 & 0 & 2 & 1 & 0 & 1 \\
\hline 78 & 1 & 1 & 0 & 2 & 0 & 0 & 0 \\
\hline 79 & 1 & 1 & 1 & 1 & 0 & 1 & 1 \\
\hline 80 & 1 & 1 & 1 & 2 & 1 & 0 & 0 \\
\hline 81 & 1 & 1 & 1 & 2 & 1 & 1 & 1 \\
\hline 82 & 1 & 1 & 1 & 1 & 0 & 1 & 1 \\
\hline 83 & 0 & 1 & 0 & 0 & 0 & 0 & 1 \\
\hline 84 & 1 & 1 & 1 & 0 & 0 & 0 & 0 \\
\hline 85 & 0 & 0 & 0 & 0 & 1 & 1 & 1 \\
\hline 86 & 1 & 0 & 0 & 0 & 0 & 1 & 1 \\
\hline 87 & 1 & 1 & 0 & 2 & 0 & 0 & 1 \\
\hline 88 & 1 & 1 & 0 & 1 & 2 & 0 & 0 \\
\hline 89 & 0 & 1 & 0 & 2 & 1 & 0 & 0 \\
\hline 90 & 1 & 1 & 1 & 2 & 0 & 0 & 1 \\
\hline 91 & 1 & 1 & 1 & 0 & 0 & 0 & 1 \\
\hline 92 & 1 & 0 & 1 & 1 & 2 & 0 & 0 \\
\hline 93 & 1 & 1 & 0 & 2 & 1 & 0 & 1 \\
\hline 94 & 1 & 1 & 1 & 0 & 0 & 1 & 0 \\
\hline 95 & 0 & 1 & 0 & 2 & 2 & 0 & 0 \\
\hline 96 & 1 & 1 & 1 & 2 & 1 & 0 & 1 \\
\hline 97 & 0 & 1 & 1 & 1 & 0 & 0 & 0 \\
\hline 98 & 1 & 1 & 0 & 0 & 2 & 1 & 1 \\
\hline 99 & 1 & 1 & 0 & 2 & 1 & 0 & 1 \\
\hline 100 & 0 & 1 & 0 & 1 & 2 & 0 & 1 \\
\hline 101 & 1 & 0 & 0 & 1 & 0 & 1 & 0 \\
\hline 102 & 1 & 1 & 0 & 2 & 2 & 0 & 1 \\
\hline 103 & 1 & 0 & 0 & 0 & 0 & 1 & 1 \\
\hline 104 & 1 & 1 & 1 & 1 & 0 & 1 & 1 \\
\hline 105 & 0 & 1 & 1 & 2 & 1 & 0 & 0 \\
\hline
\end{tabular}



Imo State Polytechnic, Umuagwo, Imo State, Nigeria)

\begin{tabular}{|c|c|c|c|c|c|c|c|}
\hline S/N & English & Maths & Gender & School type & Board & School Category & Location \\
\hline 106 & 1 & 1 & 0 & 2 & 2 & 1 & 1 \\
\hline 107 & 1 & 1 & 1 & 2 & 0 & 0 & 0 \\
\hline 108 & 1 & 1 & 1 & 1 & 1 & 1 & 1 \\
\hline 109 & 1 & 1 & 0 & 2 & 1 & 0 & 1 \\
\hline 110 & 0 & 1 & 1 & 0 & 0 & 1 & 0 \\
\hline 111 & 1 & 0 & 1 & 1 & 1 & 0 & 1 \\
\hline 112 & 1 & 1 & 1 & 2 & 0 & 1 & 0 \\
\hline 113 & 1 & 1 & 0 & 1 & 1 & 0 & 1 \\
\hline 114 & 1 & 1 & 1 & 2 & 1 & 0 & 1 \\
\hline 115 & 1 & 1 & 0 & 1 & 2 & 1 & 0 \\
\hline 116 & 0 & 1 & 1 & 2 & 1 & 1 & 1 \\
\hline 117 & 1 & 1 & 0 & 2 & 2 & 0 & 1 \\
\hline 118 & 1 & 1 & 0 & 2 & 2 & 0 & 1 \\
\hline 119 & 1 & 1 & 0 & 0 & 0 & 1 & 0 \\
\hline 120 & 0 & 0 & 0 & 1 & 0 & 0 & 0 \\
\hline 121 & 1 & 1 & 0 & 2 & 1 & 1 & 1 \\
\hline 122 & 1 & 1 & 0 & 1 & 1 & 0 & 1 \\
\hline 123 & 1 & 1 & 0 & 2 & 1 & 1 & 1 \\
\hline 124 & 1 & 1 & 1 & 1 & 1 & 0 & 1 \\
\hline 125 & 0 & 0 & 1 & 2 & 2 & 1 & 0 \\
\hline 126 & 0 & 0 & 1 & 1 & 0 & 0 & 0 \\
\hline 127 & 1 & 1 & 0 & 2 & 0 & 1 & 0 \\
\hline 128 & 0 & 0 & 1 & 1 & 2 & 0 & 1 \\
\hline 129 & 1 & 1 & 0 & 0 & 0 & 1 & 0 \\
\hline 130 & 0 & 0 & 0 & 1 & 2 & 0 & 1 \\
\hline 131 & 1 & 0 & 0 & 0 & 2 & 0 & 1 \\
\hline 132 & 1 & 1 & 0 & 0 & 2 & 1 & 1 \\
\hline 133 & 0 & 0 & 0 & 2 & 0 & 0 & 0 \\
\hline 134 & 1 & 1 & 0 & 1 & 0 & 0 & 0 \\
\hline 135 & 0 & 0 & 0 & 2 & 2 & 1 & 1 \\
\hline 136 & 1 & 1 & 1 & 1 & 1 & 0 & 1 \\
\hline 137 & 1 & 1 & 1 & 2 & 0 & 0 & 0 \\
\hline 138 & 1 & 1 & 1 & 1 & 0 & 0 & 0 \\
\hline 139 & 0 & 0 & 1 & 2 & 0 & 1 & 0 \\
\hline 140 & 1 & 1 & 0 & 1 & 0 & 0 & 1 \\
\hline 141 & 1 & 1 & 1 & 0 & 0 & 0 & 0 \\
\hline 142 & 1 & 0 & 0 & 0 & 1 & 0 & 1 \\
\hline 143 & 0 & 1 & 0 & 2 & 0 & 0 & 0 \\
\hline 144 & 1 & 1 & 0 & 2 & 1 & 1 & 1 \\
\hline 145 & 0 & 1 & 0 & 1 & 1 & 0 & 1 \\
\hline 146 & 1 & 1 & 0 & 2 & 1 & 1 & 1 \\
\hline 147 & 1 & 1 & 1 & 1 & 1 & 0 & 1 \\
\hline 148 & 0 & 1 & 1 & 2 & 1 & 1 & 1 \\
\hline 149 & 1 & 1 & 0 & 1 & 0 & 0 & 0 \\
\hline 150 & 1 & 1 & 1 & 0 & 0 & 0 & 0 \\
\hline 151 & 1 & 1 & 1 & 1 & 2 & 1 & 1 \\
\hline 152 & 0 & 1 & 1 & 0 & 0 & 0 & 0 \\
\hline 153 & 1 & 1 & 0 & 2 & 2 & 0 & 0 \\
\hline 154 & 0 & 1 & 0 & 1 & 1 & 1 & 1 \\
\hline 155 & 1 & 1 & 0 & 2 & 1 & 1 & 1 \\
\hline 156 & 1 & 1 & 1 & 1 & 1 & 0 & 0 \\
\hline 157 & 1 & 0 & 1 & 2 & 1 & 0 & 0 \\
\hline 158 & 1 & 1 & 0 & 2 & 0 & 0 & 0 \\
\hline 159 & 0 & 1 & 1 & 1 & 1 & 0 & 1 \\
\hline 160 & 0 & 1 & 0 & 2 & 2 & 1 & 1 \\
\hline 161 & 1 & 1 & 1 & 2 & 1 & 0 & 1 \\
\hline 162 & 1 & 1 & 0 & 0 & 0 & 1 & 0 \\
\hline 163 & 0 & 1 & 0 & 2 & 1 & 1 & 1 \\
\hline 164 & 1 & 1 & 0 & 0 & 1 & 0 & 1 \\
\hline 165 & 1 & 1 & 1 & 0 & 2 & 0 & 1 \\
\hline 166 & 1 & 1 & 1 & 1 & 1 & 1 & 1 \\
\hline 167 & 1 & 0 & 1 & 1 & 0 & 1 & 1 \\
\hline 168 & 0 & 1 & 0 & 2 & 1 & 0 & 1 \\
\hline
\end{tabular}




\begin{tabular}{|c|c|c|c|c|c|c|c|}
\hline $\mathbf{S} / \mathbf{N}$ & English & Maths & Gender & School type & Board & School Category & Location \\
\hline 169 & 1 & 1 & 0 & 2 & 1 & 1 & 1 \\
\hline 170 & 0 & 0 & 0 & 1 & 2 & 0 & 0 \\
\hline 171 & 1 & 1 & 1 & 1 & 1 & 1 & 1 \\
\hline 172 & 1 & 1 & 1 & 2 & 1 & 0 & 1 \\
\hline 173 & 1 & 1 & 0 & 1 & 0 & 0 & 0 \\
\hline 174 & 1 & 1 & 0 & 2 & 2 & 1 & 1 \\
\hline 175 & 1 & 1 & 0 & 2 & 0 & 1 & 0 \\
\hline 176 & 1 & 1 & 0 & 1 & 1 & 0 & 1 \\
\hline 177 & 0 & 0 & 0 & 2 & 0 & 0 & 1 \\
\hline 178 & 1 & 1 & 0 & 1 & 2 & 1 & 0 \\
\hline 179 & 1 & 1 & 1 & 2 & 1 & 0 & 1 \\
\hline 180 & 1 & 1 & 0 & 1 & 2 & 1 & 1 \\
\hline 181 & 1 & 1 & 1 & 0 & 1 & 0 & 0 \\
\hline 182 & 1 & 1 & 1 & 2 & 0 & 0 & 0 \\
\hline 183 & 0 & 0 & 1 & 1 & 1 & 1 & 1 \\
\hline 184 & 1 & 0 & 0 & 2 & 0 & 0 & 0 \\
\hline 185 & 1 & 1 & 0 & 1 & 1 & 0 & 1 \\
\hline 186 & 0 & 1 & 0 & 2 & 1 & 0 & 1 \\
\hline 187 & 1 & 1 & 1 & 2 & 0 & 1 & 0 \\
\hline 188 & 1 & 1 & 1 & 1 & 0 & 0 & 0 \\
\hline 189 & 0 & 1 & 0 & 2 & 2 & 1 & 1 \\
\hline 190 & 1 & 1 & 0 & 1 & 0 & 0 & 0 \\
\hline 191 & 0 & 1 & 1 & 2 & 1 & 0 & 1 \\
\hline 192 & 1 & 1 & 1 & 1 & 1 & 0 & 0 \\
\hline 193 & 1 & 1 & 0 & 2 & 1 & 1 & 1 \\
\hline 194 & 1 & 1 & 0 & 0 & 1 & 0 & 0 \\
\hline 195 & 0 & 1 & 0 & 1 & 1 & 0 & 1 \\
\hline 196 & 1 & 1 & 0 & 2 & 1 & 1 & 1 \\
\hline 197 & 1 & 1 & 0 & 0 & 0 & 0 & 0 \\
\hline 198 & 1 & 1 & 0 & 1 & 2 & 1 & 0 \\
\hline 199 & 1 & 0 & 1 & 2 & 0 & 0 & 0 \\
\hline 200 & 0 & 1 & 1 & 1 & 1 & 0 & 1 \\
\hline 201 & 1 & 1 & 0 & 2 & 0 & 1 & 0 \\
\hline 202 & 1 & 1 & 0 & 1 & 2 & 0 & 1 \\
\hline 203 & 1 & 1 & 1 & 2 & 1 & 1 & 0 \\
\hline 204 & 1 & 1 & 0 & 1 & 1 & 0 & 1 \\
\hline 205 & 1 & 1 & 0 & 2 & 0 & 1 & 0 \\
\hline 206 & 0 & 0 & 0 & 2 & 2 & 1 & 1 \\
\hline 207 & 1 & 1 & 0 & 1 & 1 & 0 & 0 \\
\hline 208 & 1 & 1 & 0 & 2 & 0 & 1 & 1 \\
\hline 209 & 0 & 1 & 0 & 0 & 0 & 0 & 0 \\
\hline 210 & 1 & 1 & 1 & 2 & 1 & 0 & 1 \\
\hline 211 & 1 & 1 & 1 & 1 & 1 & 0 & 0 \\
\hline 212 & 0 & 1 & 1 & 2 & 0 & 1 & 0 \\
\hline 213 & 1 & 1 & 0 & 1 & 2 & 0 & 1 \\
\hline 214 & 1 & 1 & 1 & 2 & 0 & 1 & 1 \\
\hline 215 & 1 & 0 & 1 & 1 & 0 & 0 & 0 \\
\hline 216 & 1 & 1 & 0 & 2 & 1 & 0 & 0 \\
\hline 217 & 1 & 1 & 0 & 1 & 0 & 0 & 1 \\
\hline 218 & 0 & 1 & 0 & 2 & 0 & 1 & 0 \\
\hline 219 & 1 & 1 & 0 & 1 & 1 & 0 & 1 \\
\hline 220 & 1 & 1 & 1 & 2 & 1 & 0 & 1 \\
\hline 221 & 1 & 1 & 1 & 2 & 2 & 1 & 0 \\
\hline 222 & 0 & 1 & 0 & 2 & 0 & 1 & 0 \\
\hline 223 & 1 & 1 & 0 & 2 & 0 & 0 & 1 \\
\hline 224 & 1 & 1 & 0 & 0 & 1 & 1 & 1 \\
\hline 225 & 1 & 1 & 0 & 2 & 0 & 1 & 0 \\
\hline 226 & 0 & 1 & 1 & 2 & 0 & 0 & 0 \\
\hline 227 & 1 & 1 & 0 & 2 & 2 & 1 & 1 \\
\hline 228 & 1 & 1 & 0 & 2 & 0 & 1 & 1 \\
\hline 229 & 1 & 0 & 0 & 1 & 1 & 0 & 0 \\
\hline 230 & 0 & 1 & 0 & 2 & 1 & 1 & 1 \\
\hline 231 & 1 & 1 & 0 & 2 & 0 & 1 & 1 \\
\hline 232 & 1 & 1 & 1 & 2 & 0 & 0 & 0 \\
\hline 233 & 1 & 1 & 1 & 2 & 0 & 1 & 0 \\
\hline 234 & 0 & 0 & 0 & 1 & 1 & 1 & 1 \\
\hline 235 & 1 & 1 & 1 & 0 & 0 & 0 & 0 \\
\hline
\end{tabular}



Imo State Polytechnic, Umuagwo, Imo State, Nigeria)

\begin{tabular}{|c|c|c|c|c|c|c|c|}
\hline $\mathrm{S} / \mathrm{N}$ & English & Maths & Gender & School type & Board & School Category & Location \\
\hline 236 & 1 & 1 & 0 & 2 & 2 & 1 & 0 \\
\hline 237 & 0 & 0 & 0 & 2 & 1 & 0 & 1 \\
\hline 238 & 0 & 0 & 0 & 2 & 0 & 1 & 1 \\
\hline 239 & 1 & 1 & 0 & 2 & 1 & 0 & 0 \\
\hline 240 & 0 & 0 & 0 & 2 & 0 & 1 & 1 \\
\hline 241 & 1 & 1 & 0 & 2 & 2 & 0 & 1 \\
\hline 242 & 1 & 1 & 0 & 2 & 0 & 1 & 0 \\
\hline 243 & 0 & 0 & 1 & 2 & 1 & 1 & 1 \\
\hline 244 & 1 & 0 & 0 & 2 & 2 & 0 & 1 \\
\hline 245 & 1 & 1 & 1 & 2 & 0 & 0 & 1 \\
\hline 246 & 0 & 0 & 1 & 2 & 0 & 0 & 0 \\
\hline 247 & 1 & 1 & 0 & 2 & 0 & 0 & 0 \\
\hline 248 & 1 & 1 & 0 & 0 & 1 & 0 & 1 \\
\hline 249 & 1 & 1 & 1 & 2 & 2 & 0 & 0 \\
\hline 250 & 0 & 1 & 1 & 2 & 0 & 1 & 1 \\
\hline 251 & 0 & 1 & 1 & 2 & 2 & 1 & 0 \\
\hline 252 & 0 & 1 & 0 & 2 & 0 & 1 & 1 \\
\hline 253 & 1 & 1 & 0 & 2 & 0 & 1 & 0 \\
\hline 254 & 0 & 1 & 0 & 2 & 0 & 0 & 1 \\
\hline 255 & 1 & 1 & 0 & 2 & 0 & 0 & 0 \\
\hline 256 & 1 & 0 & 0 & 2 & 2 & 1 & 0 \\
\hline 257 & 0 & 1 & 0 & 2 & 2 & 1 & 1 \\
\hline 258 & 1 & 1 & 0 & 0 & 0 & 1 & 0 \\
\hline 259 & 1 & 1 & 1 & 0 & 2 & 1 & 0 \\
\hline 260 & 1 & 1 & 0 & 2 & 2 & 0 & 1 \\
\hline 261 & 0 & 0 & 1 & 2 & 0 & 1 & 0 \\
\hline 262 & 1 & 1 & 1 & 2 & 2 & 0 & 1 \\
\hline 263 & 1 & 1 & 1 & 2 & 0 & 1 & 0 \\
\hline 264 & 1 & 1 & 1 & 2 & 0 & 1 & 0 \\
\hline 265 & 0 & 0 & 0 & 2 & 0 & 0 & 1 \\
\hline 266 & 1 & 1 & 0 & 2 & 2 & 1 & 0 \\
\hline 267 & 1 & 1 & 0 & 2 & 0 & 0 & 0 \\
\hline 268 & 1 & 0 & 0 & 0 & 0 & 1 & 1 \\
\hline 269 & 0 & 0 & 0 & 0 & 0 & 1 & 0 \\
\hline 270 & 1 & 1 & 0 & 0 & 0 & 0 & 0 \\
\hline 271 & 1 & 1 & 0 & 2 & 1 & 1 & 1 \\
\hline 272 & 0 & 0 & 0 & 2 & 1 & 1 & 0 \\
\hline 273 & 1 & 1 & 0 & 2 & 1 & 1 & 0 \\
\hline 274 & 1 & 1 & 0 & 2 & 0 & 1 & 0 \\
\hline 275 & 1 & 1 & 1 & 2 & 2 & 0 & 1 \\
\hline 276 & 0 & 1 & 0 & 2 & 0 & 1 & 0 \\
\hline 277 & 1 & 1 & 1 & 2 & 0 & 1 & 0 \\
\hline 278 & 1 & 1 & 0 & 2 & 0 & 1 & 1 \\
\hline 279 & 1 & 1 & 0 & 0 & 0 & 1 & 0 \\
\hline 280 & 0 & 1 & 1 & 2 & 0 & 0 & 1 \\
\hline 281 & 1 & 0 & 1 & 2 & 0 & 1 & 0 \\
\hline 282 & 0 & 0 & 0 & 2 & 0 & 1 & 1 \\
\hline 283 & 1 & 1 & 0 & 2 & 0 & 1 & 0 \\
\hline 284 & 0 & 0 & 0 & 2 & 0 & 0 & 1 \\
\hline 285 & 1 & 1 & 0 & 2 & 0 & 1 & 0 \\
\hline 286 & 1 & 1 & 0 & 0 & 0 & 1 & 0 \\
\hline 287 & 0 & 0 & 1 & 2 & 0 & 0 & 1 \\
\hline 288 & 1 & 1 & 0 & 2 & 0 & 0 & 0 \\
\hline 289 & 1 & 1 & 1 & 0 & 0 & 1 & 0 \\
\hline 290 & 0 & 0 & 0 & 2 & 0 & 1 & 0 \\
\hline 291 & 1 & 1 & 1 & 2 & 2 & 1 & 0 \\
\hline 292 & 0 & 0 & 1 & 2 & 0 & 1 & 1 \\
\hline 293 & 1 & 0 & 0 & 2 & 0 & 0 & 0 \\
\hline 294 & 1 & 1 & 0 & 2 & 0 & 1 & 1 \\
\hline 295 & 0 & 1 & 1 & 2 & 0 & 0 & 1 \\
\hline 296 & 1 & 1 & 0 & 2 & 2 & 1 & 1 \\
\hline 297 & 1 & 1 & 0 & 0 & 0 & 1 & 0 \\
\hline 298 & 0 & 0 & 0 & 2 & 0 & 0 & 0 \\
\hline 299 & 1 & 1 & 0 & 2 & 0 & 1 & 0 \\
\hline 300 & 1 & 1 & 0 & 0 & 0 & 1 & 0 \\
\hline
\end{tabular}




\section{References}

[1] Abdalla M.E. (2012): An Application on Multinomial Logistic Regression Model. Pok.j.stat.oper.res. Vol. VIII No. 22012 pp 271-291.

[2] Iheagwara, A.I., Nwobi, A.C, Esemokumo, P.A, and Opara, J. (2013): Investigating Predictors of Incident Hypertension Using Logistic Multiple Regression. International Journal of Applied Mathematics and Modeling, IJA2M@KINDI PUBLICATIONS. Vol.1, No.4, 1-17. October, 2013. ISSN: 2336-0054.

[3] Jewell NP. (2004). Statistics for Epidemiology. New York, Chapman \& Hall/CRC.
[4] Kleinbaum DG, Klein M. (2002). Logistic Regression: A Self-Learning Text. 2nd Ed. New York, Springer-Verlag.

[5] Sarma R and Sarmah, P. (1999): Analysis of Results Based on Grades, in Proceedings of the Second International Conference on Operations and Quantitative Management in the Global Business Environment (ICOQM), Ahmadabad, India, $3-6^{\text {th }}$ January 1999, p. $282-290$.

[6] Saha, G. and Sarmah, P. (2010): Statistical Analysis of School Examination Result with Special Reference to the State of Tripura: North-East India, Journal of Statistics.

[7] Soudarssanane M.B., Karthigeyan S., Stephen A. and Sahai, A. (2006): Key Predictors of High Blood Pressure and Hypertension among Adolescents: A Simple Prescription for Prevention. Indian Journal of Community Medicine Vol. 31, No. 3, July - September, 2006. 